\title{
Japanese Amusement Arcades in the Retro Video Game Segment: A Case of Survival Strategy
}

\author{
Hideki Takei \\ Dept. of Information Technology \& Administrative Management, Central Washington \\ University \\ 400 E University Way, Ellensburg, WA, USA
}

Tel: 1-509-963-2617

Received: March 1, 2021 Accepted: March 17, $2021 \quad$ Published: March 26, 2021

doi:10.5296/bms.v12i1.18359 URL: https://doi.org/10.5296/bms. v12i1.18359

\begin{abstract}
Amusement arcades called Game-centers have tried to find ways of surviving in Japan. Independent game-centers with limited financial capacities have mostly struggled to find the best possible way to survive (Livedoor, 2015; Thutmosev, 2015; Nomu, 2016; SPEEDA, 2017; Chiba, 2018; Kamohara, 2019). For them, a niche strategy may be the best possible strategic direction to survive (Thutmosev, 2015; Sankei, 2016; Hirakawa, 2019; Kamohara2, 2019). This paper will focus on game-centers' strategies in the retro video game niche to develop a general model of game-centers' survival strategies. We will then refine the model through interviews with senior-level employees of Japan's most successful retro game-center.
\end{abstract}

Keywords: Survival Strategy, Retro Video Games, Niche Strategy, Amusement Arcades

\section{Introduction}

In Japan, amusement arcades called game-centers have tried to find ways of surviving. Financially well-equipped large game-centers owned by major video game makers have transformed themselves into family-oriented amusement parks by actively installing family-oriented video games and other attractions. However, independent game-centers with limited financial capacities have struggled to find the best possible way to survive (Livedoor, 2015; Thutmosev, 2015; Nomu, 2016; SPEEDA, 2017; Chiba, 2018; Kamohara, 2019).

According to empirical studies, independent game-centers with limited financial capacities have focused on niche segments such as senior persons, hardcore game-players, families, shoppers at shopping malls, young couples, and kids (Thutmosev, 2015; Sankei, 2016; 
Hirakawa, 2019; Kamohara2, 2019). For example, game-centers that exclusively focus on the seniors have installed easy-to-play game machines and sizeable vending machine areas. They enjoy socializing with other seniors more than playing video games (Murakami3, 2015; Excite, 2016; Sankei, 2016). Such a tendency for socialization lets them stay in game-centers longer. They will socialize in sizeable vending machine areas and use vending machines more, which will increase profits. On the other hand, game-centers focusing on young couples have installed various sensory video game machines to play cooperatively (BEEP2, 2017; Nakajima, 2019).

While there are several niches for independent game-centers, many of them have focused on a retro video game niche. A significant motivation for this move is the lower cost of transformation. Focusing on the retro game segment is cheaper for them as they do not need to update video game machines. They already have many outdated video game machines, which they call retro game machines. They can also quickly expand variations of retro games because they can buy them at fractions of the new game machines cost (Gamespark, 2013; HRCRF2, 2014; Murakami, 2015; BEEP, 2017).

This paper will focus on game-centers' strategies in the retro video game niche to develop a general model of game-centers' survival strategies. We will then refine the model through interviews with senior-level employees of VGMR, one of Japan's most successful retro game-centers.

\section{Literature Review}

Japanese amusement arcades called game-centers were so popular in the 90 s when there were more than 30,000 centers. However, by the year 2019, we have less than 5,000 centers. Many arcade game players have left game-centers for PC games, online games, and games on their smartphones (JAMMA, 2010; Livedoor, 2015; SPEEDA, 2017; JAIA, 2018).

Emerging popular PC and online games is a significant reason for the declining numbers of game-centers. Many online games are free. The quality of PC and online games has been at the same level as video arcade games. Game players can play whenever they want to play with their PCs and smartphones.

They can even socialize with other players online (Livedoor, 2015; Nomu, 2016; SPEEDA, 2017). Independent game-centers' poor financial conditions prohibit them from buying new video games. As a result, they have lost customers (HRCRF2, 2014; Nomu2, 2016; BEEP, 2017).

A continuous increase in Japanese consumption tax has also negatively influenced game-centers because it reduced the per-play profitability of a video game machine. Game-centers can cover the tax by increasing the per-play price. However, they cannot do it quickly because of significant investments required to modify game machines to accept different coins or add electric money card readers to game machines. After all, most centers have sacrificed their profits for the consumption tax (HRCRF2, 2014; Murakami2, 2015; 
Nomu2, 2016; BEEP, 2017; Ebitsu, 2019; Uedaman, 2019).

The population of teenagers, a primary target segment, has declined because of Japan's low birth rate. Even if the teenagers visit game centers, they have spent less money as their leisure allowance has fallen in Japan's weak economy. Also, players' harmful and unhealthy images in the centers have let many teenagers stay away from game-centers (JAMMA, 2010; Thutmosev, 2015; Nomu2, 2016; RNAVI, 2019).

While market conditions look bad for game-centers, there are still business opportunities. For example, instead of teenagers, senior persons have started visiting game-centers almost every day to kill their free time. They will play easy-to-play games for hours, buy canned beverages and cigarettes from vending machines, allow their grandkids to play games. Many senior customers have visited game-centers every day to exercise their brains by playing video games. Even if they do not play games, they will visit game-centers to socialize with other seniors. According to researches, a senior tends to spend more than $\$ 200$ per month in a game-center (Thutmosev, 2015; Sankei, 2016; Chiba, 2018; Hirakawa, 2019; Kamohara2, 2019).

Game-centers can enjoy new segments as the Japanese government removed operational restrictions. After the deregulation, game-centers can operate twenty-four hours a day. They can attract new segments by adding attractive games and vending machines with comfortable rest areas. Adding arcade crane machines, arcade prize-redemption game machines, and arcade virtual game machines will especially attract young couples, young groups, and students. These game machines will also increase game-centers' profits through effective cost management of the prizes (Thutmosev, 2015; BEEP2, 2017; Chiba, 2018; Hirakawa, 2019; Kamohara, 2019).

Many game-centers have opened mini-game-centers in shopping malls to attract families and seniors with grandchildren. As the mini-game-centers tend to generate much higher per square profitability with fewer employees, they can enjoy lower labor costs and higher profits (Okada, 2009; Excite, 2016; Fujisawa, 2018; Nakajima, 2019).

In addition to new business opportunities, some have started enjoying the survivor's benefits. After 2015, game-centers' closures have been slower, while per-center profitability has increased since 2015 (Murakami, 2015; TBS, 2018; Mikado, 2019; Oguhei, 2019). Some financial institutions have financed game-centers for investments in electric money card systems, capsule toy vending machines, and new arcade game machines (Murakami, 2015; Sankei, 2016; BEEP, 2017; BEEP2, 2017; JAIA, 2018; Famitsu, 2019; Hirakawa, 2019; Kamohara2, 2019).

One of the successful niche segments which bring the survivor's benefits is a retro game segment (Hijiyan, 2013; Nomu, 2016; IGCC, 2018; TBS, 2018; Fantasista, 2019; Mikado, 2019; Robot, 2019). They have effectively used what they have: experiences, old video game machines, good old inside atmosphere, and employees' knowledge of old video games. The segment will be more prominent as the retired first-generation arcade video game players 
have started to enjoy their retirement.

There are critical points for game-centers to be successful in the niche. They need proper maintenance of the game machines and variations of famous retro games (Hijiyan, 2013; Nomu, 2016; IGCC, 2018; TBS, 2018; Fantasista, 2019; Mikado, 2019; Robot, 2019). They need to fill their spaces with retro game machines instead of arcade crane machines and arcade prize-redemption game machines. They also need to place various vending machines in small rest areas and capsule toy vending machines in front of the centers.

However, these actions are not enough for them to enjoy the survivors' benefits. They still need differentiation by developing loyal communities where hardcore retro game players regularly get together for practices, competitions, socialization, and special events (Fujisawa, 2018; IGCC, 2018; TBS, 2018; Mikado, 2019; Uedaman, 2019). Having such loyal communities will bring them more profit as players play more, buy goods more, pay for various events, and even become self-assigned promoters through word-of-mouth, publicities, and social networks (Fujisawa, 2018; IGCC, 2018; TBS, 2018; Mikado, 2019; Uedaman, 2019).

\section{A General Model of Retro Game Niche Strategy}

We developed a general niche strategy model in a retro game segment based on our literature reviews. We expect that game-centers using our model can make sustainable profits and enjoy the survivors' benefits in the retro game niche. We summarized the model in Table 1.

Our model has five strategic actions. The first action is to install many attractive retro video game machines. If game-centers already have such machines, they must do daily maintenance to keep them in good condition. In case there are not enough attractive video games, they must find traders who can sell popular video game circuits at a low cost.

The second action is to install several arcade crane machines and arcade prize-redemption game machines. Because game players tend to come with companions, their companions will play these game machines while they enjoy retro games. Game-centers welcome such companions for the additional profit.

The third action is to organize a variety of events for loyal customers to increase profits. Game-centers should let loyal customers be involved in the events because events tend to be more successful when employees and loyal customers jointly organize them. Cooperating customers also tend to promote "their events" through social media.

The fourth action is to create two community types: senior game player community and loyal retro game player community. Seniors are looking for communities where they can come every day for small talks and playing games together. In addition to retro game machines, game-centers must create comfortable rest areas where they can chat, smoke, drink, eat, and even check their health through health-related game machines and blood pressure manometers. Loyal retro game players need communities to organize various events, exchange knowledge of retro games, practice together, and socialize. 


\section{Macrothink}

The last action is to maintain minimum operation costs. Retro game-centers' operating expenses tend to be high because of the maintenance of old machines, retro video game circuit boards, and inside temperature. For example, game-centers can train employees to maintain game machines by themselves. Using rental retro game circuit boards would be a great idea to improve game variations at a low cost. Part-time employees can be managers to reduce labor costs. They should develop a great relationship with loyal customers who will be self-assigned promoters. If the rent is too expensive, they should find cheaper places.

Table 1. General Model of Retro Game Niche Strategy

1: Install many attractive retro video game machines. Maintain good conditions of the machines. Try to find ways to purcha se retro video game machines at a low cost.

2: Create store environments where both game players and their companies can have a great time. In addition to the attractive machines, install vending machines and several arcade crane machines and arcade prize -redemption game machines.

3: Organize a va riety of events for loyal and hardcore retro game players. Let the players be involved in organizing the events. Encourage the players to promote events through social media.

4: Create two types of communities: hardcore retro game players and seniors.

\section{5: Minimize operation costs, especially maintenance costs, rent, and labor} costs.

\section{Verification of the General Model}

We interviewed senior-level employees of VGMR Co. between August and October in 2019 to verify our model. We chose VGMR because it has been one of the most successful retro game-centers in Japan.

VGMR started its business in 2012 as a retro video game museum where retro game players can enjoy many retro games and support the preservation of retro game machines in functional conditions. Therefore, VGMR owns both popular retro game machines and rare retro game machines.

According to our interviews, when VGMR decided to open a retro video game-center, they took the very similar strategic moves that our model suggests.

First, VGMR installed more than 150 retro game machines in a large warehouse. They installed not only popular machines but also rare machines. Because of the extensive selections of machines, hardcore retro game players started visiting from all over Japan. As 
all employees acquired maintenance skills, anyone can maintain game machines to keep them in good condition. They also purchased retro machines at a low cost to continually expand variations of retro games.

VGMR's game-center created a comfortable rest area where anybody can enjoy vending machines, capsule toy machines, arcade crane machines, and arcade prize-redemption game machines. VGMR also improved air conditioning systems so that customers will not worry about secondhand smoke.

VGMR organized various events jointly with loyal players. For example, they organize events such as free-plays, 500-yen-plays, and game competitions every week. Event participants will promote the events on Twitter and Facebook. Employees and loyal players jointly make live coverages of the events available on YouTube.

VGMR developed two communities of customers: a loyal customer community and a senior customer community. In the dedicated customer community, members organize various events, promote them on social media, and even recruit new members. In the loyal customer community, members frequently visit to play games, use vending machines, and purchase store-brand products.

The senior customer community's members are retired first-generation arcade video game machines who want to enjoy free time to play retro games with friends or grandchildren. While they will visit almost every day to play games, they tend to spend more time at the rest area for socialization with other seniors.

They will pay good money on various vending machines during the socialization. Their grandchildren will generate profits as they play profit-making machines such as capsule toy machines, arcade crane machines, and arcade prize-redemption game machines.

VGNR has tried to minimize the operation costs of the center. VGMR relocated the center to a rural area of Saitama-prefecture to enjoy lower rent and a large car parking. VGMR's retro game-center employs only part-timers.

We could verify our model's potential effectiveness for game-centers focusing on the retro game niche through a series of interviews. However, we found something beyond our model.

\section{VGMR's Survival Strategies}

VGMR employees agreed that our model would be useful for many retro game-centers to survive. However, they pointed out that our model matched only VGMR's strategies for the retro game-center business.

According to them, the game-center is strategically essential to develop a powerful brand image as "the mecca of retro arcade video games." Their strategic focus is not the survival of the game-center but aggressive business expansions by utilizing such a powerful identity.

They believed that there would be no future for retro game-centers due to the very high 
maintenance costs of old machines and circuit boards. They noted that retro game-centers could fix or obtain spare parts for replacements for another decade. However, good maintenance would not be financially feasible because the prices of replacement parts are getting high.

They also pointed out that buying replacement parts would be impossible sooner or later. Lifespans of cathode-ray tubes of retro video game machines are reaching the end. There was no way to fix a cathode-ray-tube once it died. Similarly, repairing dead retro game circuit boards is impossible.

Therefore, VGMR will continue the retro game-center until high operation costs prohibit them from operating the center. It can then use a powerful brand identity as one of the most famous retro game-centers in Japan. It will transform the game-center into a real retro video game museum, an NPO organization that will enjoy tax benefits and grants when it cannot continue the operation.

Once VGMR secured the game center's self-sufficiency, It started developing businesses using powerful brand recognition from the retro game-center.

VGMR has actively expanded the capsule toy vending machine business through business networks that the game-center developed. Capsule toy vending machines have been popular for many game-centers, shopping malls, small department stores, and outside events because they will bring additional profits. For example, many corporate customers use capsule toy vending machines to utilize unused spaces and attract customers.

With stable business expansion, the capsule toy vending machine business has been the cash cow for VGMR. There are four primary reasons for success. First, they produced original capsule toys that are unique and attractive. Original toys can reduce production costs as VGMR can purchase a large quantity.

Simultaneously, higher volumes of the toys' sales can significantly increase VGMR's profit because VGMR does not need to pay royalties. Second, they created win-and-win relations with corporate customers by sharing profits from the capsule toys. The corporate customers will make POP ads, place capsule toy vending machines in better locations, and take care of them. Third, corporate customers are willing to make deals with VGMR, which has been recognized nationally for retro game machines and superior machine maintenance.

Finally, the operation cost is very low as anyone can visit customers, quickly clean the vending machines, and refill toys. VGMR uses two full-time employees to manage the capsule toy bending machine business.

However, as they can finish the business fast, they can use spare time for inventory controls, customer relations, maintenance, promotion, and finance. Such multi-task employees have reduced labor costs.

Recently, VGMR started promoting original miniature retro video game machines with 
capsule toy vending machines. The miniature games can sit next to the toy vending machines. They selected only popular and easy-to-play games so that anyone can play. Installations and maintenance are easy for a small and straightforward design with durable parts. VGMR did not need to increase employees for the new operation.

VGMR also started utilizing stocked video game machines and circuit boards to generate profit. Clients will visit a VGMR's inventory room to pick up game machines or circuit boards. Similar to the miniature machines, VGMR did not need to increase the number of employees. The renting service is getting popular as customers know that VGMR's machines and circuit boards are always in excellent condition.

After all, we can summarize VGMR's survival strategies as follows. First, after ensuring the retro game center's self-sustainability, prepare for the retro game center's exit strategy to become a profit retro game museum. Until then, use a powerful brand image as the most successful retro game-center in Japan to develop businesses around the image.

Second, utilize the image, business network, and know-how of retro game-center operations to develop new businesses. For VGMR, focusing on capsule toy vending machine and miniature video game machine businesses is the best direction for fully utilizing these business assets. Especially, profit sharing with clients will boost market share.

Third, minimize costs of operations such as rent, utility cost, and labor cost. Especially, multi-task employees who can do anything from maintenance to management will be powerful assets. Try to minimize the number of full-time employees.

Fourth, utilizing idling assets and inventories will be an extra. VGMR utilizes stocked retro game machines and circuit boards by lending to other game-centers.

\section{Summary}

We verified the effectiveness of our niche strategy model. Suppose an independent game-center with limited financial capacity wants to survive in Japan's retro video game segment. In that case, they should (1) install many attractive retro video game machines in good condition, (2) make store environments comfortable for game players and their companies, (3) organize a variety of events for hardcore retro game players with loyal customers, (4) create communities for hardcore retro game players and seniors, and (5) minimize operation costs.

At the same time, we learned that the retro video game segment would not exist forever. Therefore, game-centers in the niche must develop exit strategies to move on to new businesses if they want to continue their operations. 


\section{References}

BEEP. (2017, March 19). Game over of game center business. Retrieved 2019, from Game Music: https://gmdisc.com/archives/984

BEEP2. (2017, March 8). Memories of game centers. Retrieved 2019, from Game Music: https://gmdisc.com/archives/1044

Chiba, C. (2018, May 15). Revivals of Game Centers in Shopping Malls. Retrieved 2019, from Citrus: https://citrus-net.jp/article/57933

Ebitsu. (2019, September 8). A store manager of a game center said, "We may have to close by the end of September.". Retrieved 2019, from Ebitsu: http://ebitsu.net/archives/80104040.html

Excite. (2016, March 9). Seniors in day-time game centers! Socialization? Prevention of arzheimer? $\quad$ Retrieved 2019, from Excite News: https://www.excite.co.jp/news/article/HealthPress_201603_post_2284/

Famitsu. (2019, September 5). Tokyo Game Show 2019. Retrieved 2019, from Famitsu: https://www.famitsu.com/news/201909/05182612.html

Fantasista. (2019, September 3). Welcome to Fantasista. Retrieved 2019, from Fantasista: https://yaplog.jp/am-fantasista/

Fujisawa, B. (2018, January 29). The Mecca of Retro Games in Northern Japan "Dhinos Sapporo Chиo.” Retrieved 2019, from IGCC: https://igcc.jp/ディノス札幌中央/

Gamespark. (2013, May 23). Interview with Mr. Tetsuro Tuji, Director of Japan Museum of Video Game. Retrieved 2019, from Games https://www.gamespark.jp/article/2013/05/23/40955.html

Hijiyan. (2013, November 12). Game Center Robot. Retrieved 2019, from Tablekotainahibi: http://bz504178zb.blog.fc2.com/blog-entry-239.html

Hirakawa, S. (2019, May 9). The way of game centers' survival. Retrieved 2019, from Note: https://note.mu/hey_game/n/n2e345fd7c330

HRCRF2. (2014, March 11). Ways of Game Centers' Survival \#1. Retrieved 2019, from HR CRF2: https://blogs.yahoo.co.jp/hr_crf2/64166315.html

IGCC. (2018, April 26). The Mecca of Retro Video Game in North-Kanto area: VGM Robot Fukaya. Retrieved 2019, from IGCC: https://igcc.jp/vgm ロボット/

JAIA. (2018, March 1). Survey of the Amusement Industry of Japan (2018). Retrieved 2019, from JAIA: https://jaia.jp/wp-content/uploads/2018/03/アミューズメント実態調査 H28 年 度要約データ.pdf

JAMMA. (2010, December 31). Survey of the Amusement Industry of Japan (2010). 
Retrieved 2019, from JAMMA: http://www.jamma.or.jp/reference/data/survey_h22.pdf

Kamohara, M. (2019, April 23). The number of game centers became 1/5 of the booming era. Retrieved 2019, from Yahoo News: https://news.yahoo.co.jp/byline/shigiharamorihiro/20190423-00122897/

Kamohara2, M. (2019, July 8). The Reality of Chairs in Game Centers. Retrieved 2019, from DenFamicoGamer: https://news.denfaminicogamer.jp/kikakuthetower/190708b

Livedoor. (2015, October 23). Elders go to game-centers. Do they give the centers profits? Retrieved 2019, from Livedoor News: https://news.livedoor.com/article/detail/10743082/

Mikado. (2019, September 2). Welcome to Mikado. Retrieved 2019, from Mikado: http://mi-ka-do.net/baba/

Murakami, M. (2015, December 12). Game Centers Forever: Introducing E-Money. Retrieved 2019, from Itmedia: https://www.itmedia.co.jp/lifestyle/articles/1512/12/news007.html

Murakami2, M. (2015, December 12). Game Center Forever: Introducing E-Money \#2. Retrieved 2019, from Itmedia: https://www.itmedia.co.jp/lifestyle/articles/1512/12/news007_2.html

Murakami3, M. (2015, December 8). Sphygmomanometer and Radio Exercise: Can game centers become social clubs of seniors? Retrieved 2019, from Itmedia: https://www.itmedia.co.jp/lifestyle/articles/1512/08/news020.html

Nakajima, Y. (2019, June 3). Crane Games are hot! Making profits! Retrieved 2019, from Asahi Newspaper

Digital: https://www.asahi.com/articles/ASM5R6HHMM5RPLFA00D.html

Nomu. (2016, August 1). Survival of Game Centers Vol 1. Retrieved 2019, from BayonWeb: http://bayon-game.com/?p=12603

Nomu2. (2016, August 8). The survival of game centers Vol 2. Retrieved 2019, from Bayon Web: http://bayon-game.com/?p=12773

Oguhei. (2019, April 13). Report: Super2X event at Robot Fukaya. Retrieved 2019, from Oguhei: https://oguhei.net/2018/04/21/gamecenter_fukayarobo/

Okada, Y. (2009, August 10). Video Game Cener Segment Diminishing: Taito's survival strategy. $\quad$ Retrieved 2019, from Itmedia: https://www.itmedia.co.jp/news/articles/0908/10/news016.html

RNAVI. (2019, May 31). DataBase for Game Center Industry. Retrieved 2019, from Research Navi of Japan National Library: https://rnavi.ndl.go.jp/research_guide/entry/theme-honbun-102717.php

Robot. (2019, August 5). Welcome to Robot. Retrieved 2019, from Robot: 
http://www.roboto.co.jp/

Sankei. (2016, January 13). Troubles with more expensive prizes as a way of game centers' survival. $\quad$ Retrieved 2019, from Sankei News: https://www.sankei.com/affairs/news/160113/afr1601130002-n1.html

SPEEDA. (2017, July 8). The Future of Game Centers. Retrieved 2019, from News Picks: https://newspicks.com/news/2354788/body/

TBS. (2018, February 4). A retro game-center is making a profit of 10000000-yen per month. Retrieved 2019, from TBS: https://www.tbs.co.jp/gacchiri/archives/2018/0204.html

Thutmosev. (2015, November 23). Seniors' Game Centers Exist? 20\% of the total game center population is now seniors. Retrieved 2019, from The World News: http://www.thutmosev.com/archives/48506321.html

Uedaman. (2019, February 5). Will game centers die? Suggestions for game centers to survive. $\quad$ Retrieved 2019, from Movie Scoop: https://doga.hikakujoho.com/moviescoop/55176200001518/

\section{Copyright}

Copyright for this article is retained by the author(s), with first publication rights granted to the journal.

This is an open-access article distributed under the terms and conditions of the Creative Commons Attribution license (http://creativecommons.org/licenses/by/4.0/). 